\title{
Does a cold rainy day keep the patients away?
}

\author{
Jennifer A. Davidson, MBBS, FACEM ${ }^{a, *}$, William Sargent, $M B C h B^{a}$, \\ Anna Holdgate, MBBS, FACEM, MMed ${ }^{\mathrm{b}}$, \\ Bin Jalaludin, MBBS MRCP (UK) FAFPHM PhDc
}

\footnotetext{
a Department of Emergency Medicine, Liverpool Hospital, Locked Bag 7103, Liverpool BC, NSW 1871, Australia

${ }^{\mathrm{b}}$ Director of Emergency Medicine Research Unit, Liverpool Hospital, University of New South Wales, Australia

' Centre for Research, Evidence Management and Surveillance, Sydney South West Area Health Service and School of Public Health and Community, Medicine University of New South Wales, Australia
}

Received 20 August 2007; accepted 2 October 2007

\section{KEYWORDS \\ Rainfall; \\ Temperature; \\ Emergency \\ department \\ presentations}

\begin{abstract}
Summary
Objective: To explore the relationship between the number of patients presenting to the Emergency Department and the weather. To determine if the number of non-urgent cases presenting to the ED is affected by the weather.

Methods: Retrospective review of all presentations to the ED of a tertiary referral hospital in the south-west of Sydney, Australia over a 1 year period. Total daily numbers of patient presentations and their triage acuity were correlated with temperature, rainfall, day of the week and the absence or presence of a Public holiday.

Results: During the study period 46,903 patients presented to the ED with an average of 128.5 patients a day. Rainfall occurred on 135 days. There was a positive correlation between day of the week $(P<0.001)$ and the presence of a public holiday $(P<0.001)$ on ED attendances. Increasing maximum daily temperature was also associated with a rise in ED presentations $(P=0.04)$. Daily rainfall did not significantly influence ED attendance numbers $(P=0.07)$. The presence of a Public holiday was the only significant variable affecting the numbers of nonurgent presentations $(P=0.003)$.

Conclusions: Meteorological factors such as rainfall and temperature impact minimally on ED attendances. Day of the week and Public holidays are more important variables impacting on total ED workload and resource planning should be guided by this.

(c) 2007 Published by Elsevier Ltd on behalf of College of Emergency Nursing Australasia Ltd.
\end{abstract}

\section{Introduction}

\footnotetext{
* Corresponding author. Tel.: +61 29828 3990;

fax: +61298283984 .

E-mail address: Jennifer.davidson@swsahs.nsw.gov.au (J.A. Davidson).
}

Meteorological factors have long been associated with the incidence of disease. An association has been documented between thunderstorm activity and increased asthma presentations to the Emergency Department (ED). ${ }^{1-3}$ Other

1574-6267/\$ - see front matter @ 2007 Published by Elsevier Ltd on behalf of College of Emergency Nursing Australasia Ltd. doi:10.1016/j.aenj.2007.10.001 
studies that purport causality between climate and health include the effect of high temperatures on presentations of schizophrenia ${ }^{4}$ and also pelvic pain. ${ }^{5}$

It is not uncommon for Emergency health care workers to comment on the impact of the day's weather on likely presentations, both number and quality. One Norwegian study looked at hospital admission rates for adults with respect to rainfall and found no correlation. ${ }^{6}$ A study performed in the USA looked at the relationship between the number and acuity of paediatric ED visits and the weather. They found no significant difference in presentations and 'unfavourable' weather conditions. ${ }^{7}$

Identifying variables that influence ED attendance patterns may help to streamline appropriate resource allocation. This study aims to investigate the relationship between total numbers of patient presentations to the ED and the weather, and to determine if the number of nonurgent cases is affected by climactic conditions.

\section{Methods}

The study was conducted in the Emergency Department (ED), of a tertiary referral and trauma centre with a mixed adult and paediatric population located in south-west Sydney, Australia. Total daily attendances and triage acuity of patients who presented to the ED between 1st July 2004 and 30th June 2005 were collated using the Emergency Department Information Database (EDIS). Patients were triaged in accordance with the Australasian Triage Scale. ${ }^{8}$ Daily rainfall and maximum temperature as recorded by the Bureau of Meteorology (BOM) ${ }^{9}$ at the local weather station was correlated with daily ED presentations. This weather station is volunteer run and World Meteorological Organization (WMO) accredited. It is situated $4 \mathrm{~km}$ west of the hospital campus.

\section{Data analysis}

The main outcomes were total number of patients presenting per day (TNP) and percentage of patients allocated triage category 5 (TC5) per day. ${ }^{7}$ Category 5 patients were used as a surrogate marker for 'non-urgent' cases. Maximum daily temperature, daily rainfall, day of week and presence or absence of a Public holiday were consid- ered as potentially significant factors. Day of week (DOW) and Public holidays (PH) were included as previous data from our department indicated that presentations were frequently higher on weekends and public holidays. As rainfall was not normally distributed, it was categorised into $<5 \mathrm{~mm}$ and $5 \geq \mathrm{mm}$ per day. In the univariate analysis, means across groups were compared using the $t$-test or analysis of variance, and relationships between continuous variables were explored using Pearson's correlation coefficient.

Linear regression models for the two outcomes were developed to determine whether meteorological factors were a predictor of the number of daily ED visits, after adjusting for other significant variables. A $P$-value of $<0.25$ was used to screen for variables to be included in the baseline model. Backward elimination was used to determine the final model with a $P$-value of less than 0.05 taken as denoting statistical significance. Data were analysed using SPSS version 13.0.

\section{Results}

Over the 12 month period, 46,903 patients presented to the ED with an average of 128.5 patients per day. Rainfall was recorded on 135 days, though on 50 of these days rainfall was less than $1 \mathrm{~mm}$. The pattern of rainfall, daily maximum temperature and daily presentations to ED are summarised in Fig. 1.

\section{Total number of patients presenting per day}

In the univariate analysis (Table 1), there was a weak but significant correlation between TNP and maximum daily temperature $(P=0.04)$, and a significant relationship with DOW and $\mathrm{PH}$. There was a trend towards fewer presentations on rainy days but this was not significant.

In the regression analysis, maximum daily temperature, DOW and PH all had a significant relationship to TNP. Rainfall did not significantly impact on TNP after allowing for these factors $(P=0.07)$. Although there was a weak correlation between rainfall and temperature $(R=0.13, P=0.02)$, there was no evidence of collinearity in the regression model.

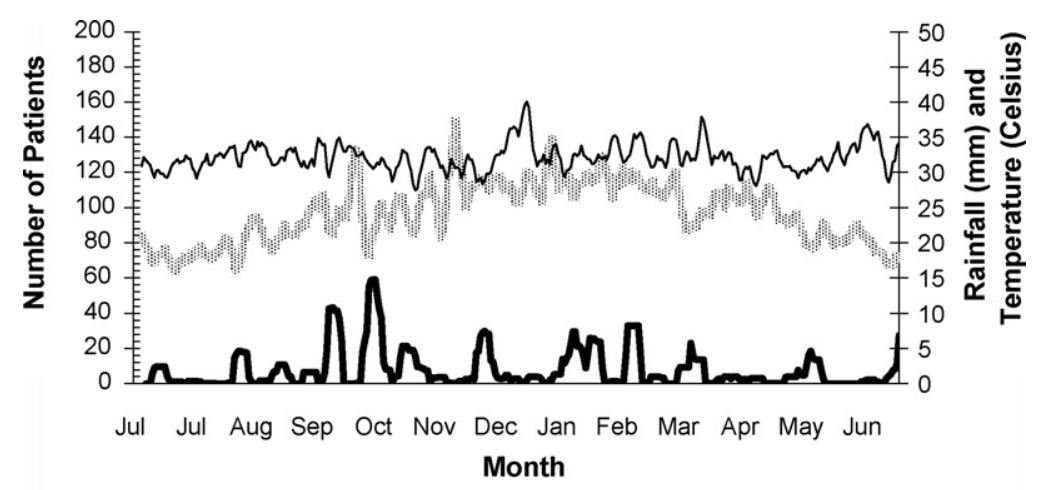

Maximum Temperature $\longrightarrow$ Rainfall $\longrightarrow$ Number Of Patients

Figure 1 Daily rainfall, maximum temperature and presentations over 1 year. 
Table 1 Univariate analysis of factors impacting on total daily presentations

\begin{tabular}{ll}
\hline & Mean TNPa (S.D.) \\
\hline Maximum daily temperature ${ }^{\mathrm{b}}$ (mean $24.1^{\circ} \mathrm{C}$, range $\left.12.5-41.2\right)$ & Correlation coefficient, 0.11 \\
Daily rainfallc: & \\
$\quad<5 \mathrm{~mm}(n=324)$ & $129.0(13.5)$ \\
$\geq 5 \mathrm{~mm}(n=41)$ & $127.9(12.3)$ \\
Day of week ${ }^{\mathrm{c}}:$ & \\
Monday & $134.1(12.8)$ \\
Tuesday & $124.1(11.2)$ \\
Wednesday & $123.3(12.1)$ \\
$\quad$ Thursday & $124.5(11.7)$ \\
$\quad$ Friday & $123.5(11.1)$ \\
Saturday & $130.3(14.2)$ \\
Sunday & $139.8(12.8)$ \\
Public Holidayc: & \\
Yes $(n=10)$ & $148.3(8.6)$ \\
No $(n=355)$ & $127.9(13.1)$ \\
\hline a TNP, total patients presenting to ED per calendar day. & \\
b Pearson's correlation. & \\
c $t$-test or ANOVA. & \\
\hline
\end{tabular}

After allowing for DOW and $\mathrm{PH}$, there were approximately 0.24 (95\% Cl: 0.15 to 0.47$)$ additional patients per day for every $1{ }^{\circ} \mathrm{C}$ increase in temperature $(P=0.04)$.

\section{Proportion of 'non-urgent' patients per day}

Triage category 5 patients accounted, on average, for $4 \%$ of daily presentations (range $0-14.5 \%$ ). There was no significant relationship between proportion of TC5 patients and temperature $(P=0.5)$, rainfall $(P=0.4)$ or DOW $(P=0.4)$ in the unadjusted analysis. A significantly higher proportion of TC5 patients presented on $\mathrm{PH}$ compared with non- $\mathrm{PH}(6.1 \%$ v $4.0 \%, P=0.003)$.

After allowing for $\mathrm{PH}$, neither temperature nor rainfall was associated with a change in proportion of TC 5 presenting each day.

\section{Discussion}

The results both support and dispel some commonly held beliefs about patterns of ED attendance. As anecdotally believed, peak patient workload occurred on weekends, Mondays and public holidays. This information should support greater staffing on those days.

Increasing maximum daily temperature had a positive correlation with ED presentations. However, although this finding was statistically significant, the clinical impact of temperature is relatively small with fewer than three additional patients for every $10^{\circ} \mathrm{C}$ increase in temperature. Although we allowed for Public holidays in our analysis, it should also be recognised that half the $\mathrm{PH}$ occur over the Christmas/New Year period (mid-summer), when even on non-PH routine non emergency medical services are often unavailable to the public. Thus this may have exaggerated the apparent impact of higher tem- peratures. Interestingly, our data did not support the commonly perceived relationship between increased attendances and the winter season. The apparent 'winter peak' may relate more to higher acuity casemix, longer lengths of stay and increased access block, all of which will increase the number of patients in the ED at any one time.

Rainfall did not significantly impact on TNP in our study, despite the commonly held belief of many ED physicians that a wet day discourages patient attendances. Rainfall may still discourage patient presentations to the ED if only temporarily, however correlation and analysis of hourly rainfall and attendances would be required and this was beyond the scope of this paper. However, rainfall was generally very low in the study period with only 41 days recording $5 \mathrm{~mm}$ or more of rain. Had the study been duplicated in a country with higher annual precipitation the impact observed may have been different.

The only significant factor identified that influenced nonurgent patient presentations was the presence of a $\mathrm{PH}$. The Christmas/New Year period with decreased availability of GP, outpatient and community services undoubtedly contributed to the observed peak in non-urgent ED attendances over this time.

There are several limitations to the study. There are other potential confounding variables that may influence daily ED presentations such as relative humidity that we did not consider in our data analysis. Category 5 patients were selected as a surrogate marker of non-urgent cases, however, we recognise that a subgroup of these patients indeed requires hospital admission, and that a proportion of patients in other triage categories may also be classified as not in need of ED-based care. Individual triage competencies will also result in interrater variability between staff and influence which patients are allocated a category 5. 


\section{Conclusion}

Meteorological factors play a minor role in determining daily presentations to the ED. More predictable factors, such as day of week and Public holidays have much stronger impact on daily presentations and resource planning should be guided by this.

\section{Competing interests/Funding}

There are no competing interests and no funding associated with the preparation of this manuscript.

\section{Acknowledgements}

The authors would like to thank Cathrine McDonald for her help in data collection.

\section{References}

1. Bellomo R, Gigliotti P, Treloar A, Holmes P, Suphioglu C, Singh $M B$, et al. Two consecutive thunderstorm associated epidemics of asthma in the city of Melbourne. Med J Aust 1992;156: 834-7.

2. Dales RE, Sabit C, Judek S, Dann T, Coates F, Brook JR, et al. The role of fungal spores in thunderstorm asthma. Chest 2003; 123(Mar 3):745-50.

3. Marks GB, Colquhoun JR, Girgis ST, Koski MH, Treloar AB, Hansen $P$, et al. Thunderstorm outflows preceding epidemics of asthma during spring and summer. Thorax 2001;56:468-71.

4. Shiloh R, Shapira A, Potchter O, Hermesh H, Popper M, Weizman A. Effects of climate on admission rates of schizophrenia patients to psychiatric hospitals. Eur Psychiat 2005;20(Jan 1):61-4.

5. Bianchi-Demicheli F, Ludicke F, Spinedi F, Major AL, Kulier R, Campana A, et al. Association between weather conditions and the incidence of emergency gynecological consultations. Gynecol Obstet Inves 2001;51(1):55-9.

6. Tollefsen NH, Dickstein K. Are emergency admissions to medical departments dependent on weather? Tidsskr Nor Laegeforen 2000;120(Dec 30):3678-9.

7. Attia MW, Edward R. Effect of weather on the number and the nature of visits to a pediatric ED. Am J Emerg Med 1998;16(Jul 4):374-5.

8. ACEM, The Australasian Triage Scale. Australasian College for Emergency Medicine, policy document, 2004.

9. Australian Government Bureau of Meteorology. Daily Weather Observations. Available at: http://www.bom.gov.au Accessed: August 2005. 